\title{
Healthy ageing - happy ageing: Health Promotion for Older People in Italy
}

\author{
Andrea Poscia ${ }^{1}$, Roberto Falvo ${ }^{1}$, Daniele Ignazio La Milia ${ }^{1}$, \\ Agnese Collamati ${ }^{2}$, Francesca Pelliccia ${ }^{1}$, Iwona Kowalska-Bobko ${ }^{3}$, \\ Alicja Domagała ${ }^{3}$, Walter Ricciardi ${ }^{1,4}$, Nicola Magnavita ${ }^{1}$, \\ Umberto Moscato ${ }^{1}$
}

\begin{abstract}
${ }^{1}$ Department of Public Health, Università Cattolica del Sacro Cuore, Rome, Italy $;{ }^{2}$ Department of Gerontology, Orthopaedics and Neuroscience, Università Cattolica del Sacro Cuore, Rome, Italy; ${ }^{3}$ Institute of Public Health, Faculty of Health Sciences, Jagiellonian University Medical College, Cracow, Poland; ${ }^{4}$ National Institute of Health, Rome, Italy

Address for correspondence: Roberto Falvo, Institute of Public Health, Università Cattolica del Sacro Cuore di Roma, Largo Francesco Vito, 1 - 00168 Roma, falvoroberto@gmail.com
\end{abstract}

\section{Acknowledgments}

The fundamental contributions to the report came from the experts, professionals and street level health promoters who completed a questionnaire and/or were interviewed: Serenella Fucksia (Italian Senate), Daniela Galeone and Giovanna Giannetti (Ministry of Health), Alfredo Ferrante (Ministry of labour and social policy), Antonio Mastrovincenzo (Council of the Marche Region), Alberto Perra (National Institute of Health), Gilberto Gentili (General Manager ASL Alessandria \& National President CARD), Gianluigi de Palo and Emma Ciccarelli (Family Associations Forum), Giuliano Carrozzi and Francesco Venturelli (Local Health Authority Modena), Antonietta Spadea (Local Health Authority Roma1), Carlo Annona (Local Health Authority Matera), Giovanni Peliti (General Practitioner Roma1 and member of the board of health promoter), Nicoletta Teodosi (Municipality of Cerveteri), Luca Vecchi (National Association of Italian Municipalities, Welfare Department).

\section{Abstract}

Health Promotion for Older People (HP4OP) is a relevant issue in Italy, one of the countries where people live the longest. Strategies, programmes and projects are set and planned at the national level, mainly by the Ministry of Health within the National Health Service, but strong competencies, funds and resources derive also from the Government, the Ministry of Labour and Social Policies and the Ministry of Internal Affairs. Moreover, European funds contribute to programmes and projects in this field. After strategic implementation at the regional level, programmes and projects are carried out at the local level under the National Health Service, mainly by the Local Health Authorities in conjunction with municipalities and other relevant stakeholders such as NGOs, the voluntary sector, families and educational and religious entities, etc. Even though Italy has been engaged in HP40P to improve active life expectancy since 1992, a lack of planning and resources for HP40P, policy diversification at the regional level and a prevailing interest in care-assistance rather than health promotion and prevention have prevented consistent implementation of HP40P throughout the country.

Key words: Health Promotion, elderly, Public Health, active ageing, policy, Italy 


\section{Introduction}

The objective of the Italian Country Profile in the area of health promotion for older people is to collect and present essential information on the organisation and funding of these activities in the context of the systemic arrangement of health care and public health. The institutional and financial description includes the primary institutions responsible for carrying out tasks in this area - even if health promotion is just a fraction of their responsibility.

On the basis of expert opinions collected within Work Package 6 of the Pro-Health 65+ Project and described elsewhere [1], the most important fields engaged in HP4OP in Italy were identified as the health, social assistance and regional/local authority sectors. The complex picture of health promotion activities targeted at older people was analysed by reviewing the literature and interviewing national and local experts belonging to the three aforementioned sectors. The primary sources of information were scientific papers and grey literature as well as other materials: e.g. government websites, strategic documents, programmes and projects, guidelines and other publicly available sources that were accessible in Italian or in English. A fundamental contribution to knowledge of the role of institutions acting in HP4OP in Italy came from the experts, professionals and street level health promoters who kindly accepted the authors' interview and were mentioned in the "acknowledgment" section.

\section{The Italian context for Public Health and Health Promotion for Older Adults}

In 1978, the post-war social security system that included a social health insurance system administered by sickness funds was substituted by a tax-funded National Health Service (Servizio Sanitario Nazionale - SSN), based on the Beveridge model that guaranteed comprehensive health care throughout the country [2]. In the last 20 years a process of decentralization has led to a strong empowerment and autonomy of regional authorities, notably in three major reforms which reshaped the system (Legislative Decrees 502/1992, 517/1993 and 229/1999). These reforms introduced elements of an internal market and gave managerial autonomy to Local Health Authorities (Aziende Sanitarie Locali - ASLs) and hospital trusts [3-5]. Finally, with the 2001 reform of Constitutional Law, Regional Governments gained even more autonomy and responsibility, thus transforming Italy's healthcare system into a "regionally" organised National Health Service [6].

At the national level, the Ministry of Health is the leading institution in the field of health promotion but the Ministry of Labour and Social Policies and the Ministry of Internal Affairs are also partially involved directly or indirectly in HP programme management and funding. Currently, the Ministry of Labour and Social Policies, according to Law 328/2000 [7], manages the National Fund for Social Policies (addressed to regional governments) while the Ministry of Internal Affairs, through the action plan for social cohesion (Piano d'azione Coesione-Pac), promotes the national plan for the delivery of care services to children and dependent/non self-sufficient elderly (the plan is addressed to Municipalities). The Parliament also plays a direct role in this field. In June 2016, the parliamentary "Active ageing" group was founded to represent the needs of older citizens and to encourage the Government to introduce policies in favour of active and healthy ageing.

The Ministry of Health has a stewardship role that involves establishing the fundamental principles and goals of the health system through a National Health Plan (recently called the Pact for Health) or a State/Region (plus Autonomous Province) Agreement on Health [8] and determining the core benefit package of health services (called LEA, or essential levels of assistance, financed by general taxation) to be guaranteed across the country free of charge or by cost sharing, and allocating part of the national health fund to the regions. Public health and health promotion, including health promotion for the elderly, are included in the National Prevention Plan, issued by the Ministry of Health [9].

Regional governments are responsible for and have exclusive authority over execution-level planning and delivery of health care, preventive and promotion services as well as health-related fields such as work safety, food safety and scientific research [10]. It's the Regional Health Department that is in charge of the implementation of the Regional Health Plan and the Regional Plan for Prevention, which are based on guidelines set out in the National Prevention Plan. Moreover, Regional Health Departments, together with the Regional Department of Social Policies and a Standing Conference for Regional Health and Social Care Planning, are responsible for the coordination of health and social care.

At the local level, geographically based ASLs deliver public health, health promotion, community health services and primary care. The local departments of prevention are in charge of the planning and coordination of health promotion projects and activities. Integration between social and health sector actions and programmes happens at this level through a specific functional unit called District that collaborates with Municipalities, NGOs and civil society in order to plan and implement integrated projects and actions in the field of health promotion, including that for the elderly [2].

The main actors involved in Health Promotion for the elderly in Italy are shown in Figure 1, while the main indicators related to the Italian health system are listed in Box 1. 


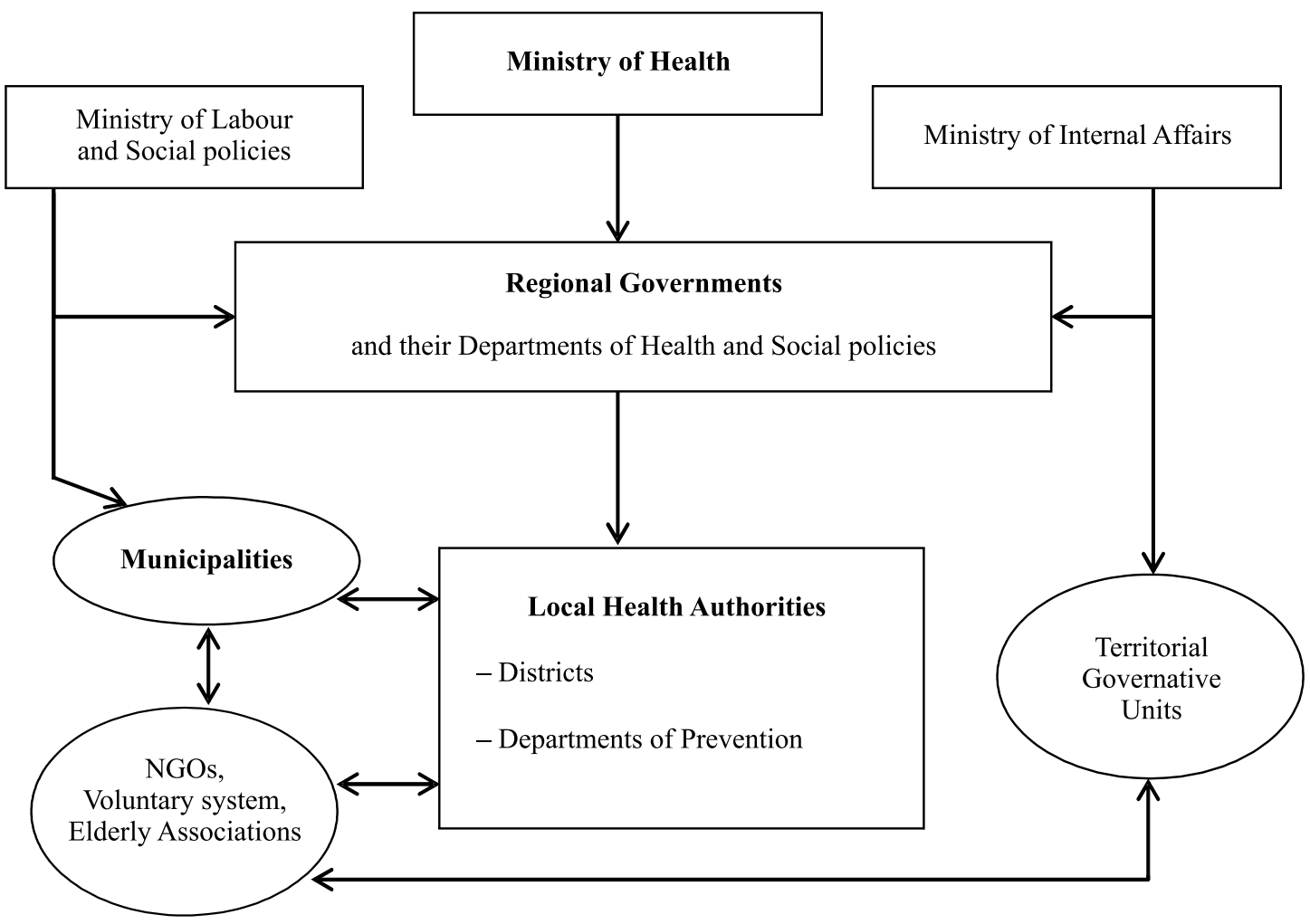

Figure 1. Actors playing a role in Health Promotion for the elderly in Italy.

Source: The Authors, 2016.

- total health expenditure per capita in 2013 was $\$ 3,155$ [11, 12], $(3,077$ in current PPP per capita $[13,14])$ and has dropped by $3.5 \%$ in real terms in the last 3 years due to a number of cost-containment measures that have been taken in the wake of the economic crisis to reduce public spending on health [15];

- total health expenditure as \% of GDP rose from $7.9 \%$ in 2000 to 9.1 in 2014 but it is still below the OECD average; the same health expenditure as \% of GDP excluding capital investment expenditure was $8.8 \%$ of GDP in 2013 , slightly below the OECD average of $8.9 \%$, this value can be explained by the relatively weak GDP growth for Italy over that period [15];

- health expenditures by financing schemes (HF NHA), in 2000 and 2013.

Public sources made up $78.2 \%$ of total health-care spending, with private spending accounting for the remaining $21.8 \%$, mainly in the form of out of pocket payments (17.8\%) for diagnostic procedures (laboratory tests and imaging), pharmaceuticals, specialist visits and for unjustified (non-urgent) interventions provided in hospital emergency departments. Only about $1 \%$ of the total health-care expenditure is funded by private health insurance [15]. For comparison, in 2000, public health expenditure accounted for about $72 \%$ and private health expenditure accounted for around $28 \%$, with out of pocket expenditures accounting for around $24 \%$.

Box 1. Health system indicators.

Source: Own work.

\subsection{Health status of older people in Itialy}

Like many other developed countries in the world, Italy is currently facing increasingly complex and systemic social challenges due to demographic changes that have dramatically modified life expectancy and the composition of the population (see Box 2). In 2014, life expectancy at birth was 82.5 years $(84.8$ for females and
79.9 for males), while at 65 it was 21.2 years ( 22.8 and 19.2 , respectively) [16]. The number of Italians aged over 65 could almost double between 2011 and 2065 to reach about $33 \%$ of the entire population [16]. More attention is paid to the quality of life than the quantity. It is estimated that in 2013, the healthy life years for people aged $65+$ were 7.3 and 7.8 for females and males, respectively: around one third of life expectancy at that age [16]. 
- old age dependency ratio (65+) trends and prognosis (2020, 2030), the actual old age dependency ratio, i.e. the ratio between the number
of persons aged 65 and over (age when they are generally economically inactive) and the number of persons aged between 15 and 64 in 2015
was estimated to be $\mathbf{3 3 . 3}$ (vs. EU 28 at 28.1 ). The estimates for this indicator in 2020 and 2030 are respectively $\mathbf{3 4 . 9}$ and $\mathbf{4 0 . 8}$;
- the shares of the population aged $\mathbf{6 5}+, \mathbf{6 5 - 7 9}$, and $\mathbf{8 0}+$ in relation to the total population in 2015 were $21.4 \%, 15 \%$ and $6.4 \%$ respectively;
- life expectancy at birth in 2014 was $\mathbf{8 5 . 6}$ in females and $\mathbf{8 0 . 7}$ for males; 83.2 as a whole;
- life expectancy at $\mathbf{6 5}$ in $\mathbf{2 0 1 4}$ was 21.2 total, $\mathbf{2 2 . 8}$ for females, $\mathbf{1 9 . 2}$ for males;
- healthy life years $\mathbf{6 5}+$ in 2014 were equal to 7.3 and $\mathbf{7 . 8}$ for females and males respectively.

Box 2. Population ageing indicators [16].

Source: Own work.

The "PASSI d'Argento" National Surveillance System reported that in 2013 around $64 \%$ of people $65+$ suffered from at least one chronic disease (33\% cardiovascular diseases, 25\% COPD; $20 \%$ diabetes; $13 \%$ cancer), while $13 \%$ had more than three chronic diseases [17]. More generally, $39 \%$ of the elderly $(65+)$ were in good health with a low risk of illness, $24 \%$ were in good health but at risk of illness, $21 \%$ were infirm and at risk of disability and $16 \%$ were disabled. On the other hand, while the proportion of smokers declines with age (19\%, $13 \%$ and $5 \%$, respectively in the $60-64,65-74$, and $75+$ age groups), the prevalence of alcohol consumers at risk among the elderly (65-74) remains high (21\% in 2014), as does the percentage of elderly at risk due to physical inactivity (44\%) (see Box 3).

\section{Funding of Public Health and Health Promotion for Odder Adults - potential sources and main institutions}

The Italian national health system is based mainly on a tax-financed Beveridge model and is supplemented by co-payments for pharmaceuticals and outpatient care. Based on OECD data, in 2013 spending on health (excluding investment expenditure in the health sector) amounted to $8.8 \%$ of GDP, slightly below the OECD average of $8.9 \%$ (see Box 1).

Public sources made up $78.2 \%$ of total health-care spending, with private spending, mainly in the form of out-of-pocket payments (OOP) (17.8\%), accounting for the remainder. Only about $1 \%$ of the total health-care expenditure is funded by private health insurance [2]. The share of government spending in Italy as a share of total spending on health is slightly above the OECD average, while out-of-pocket spending is relatively high compared with other western European countries such as France, Germany and the United Kingdom, although still well below some other southern European countries such as Greece and Portugal.

The public health-care system is financed primarily through IRAP, an earmarked corporate value added tax on companies and salaries paid to public sector employees. The tax is pooled nationally and allocated back to the regions, which have the flexibility to raise the level of taxation. Furthermore, Regions surcharge the national income tax (addizionale IRPEF) and receive from the central government a fixed proportion of national valueadded tax (VAT) revenue [2].
The National Health Fund for 2014 amounted to about $€ 110$ billion. The Ministry of Health defines the yearly regional funding needs according to a mix of weighed capitation and historical spending. The age of residents is one of the factors that influence the weighted capitation system. The greater part of the National Health Fund is divided into three broad service areas that each region should guarantee as part of the benefit package: primary care $(44 \%)$, secondary-tertiary care $(51 \%)$ and prevention $(5 \%)$. As mentioned above, regions have autonomy concerning the revenue side of the regional budget and complete freedom over the allocation of funds among the regional functions. Thus, the percentages fixed by the Ministry of Health can be modulated at the regional level in accordance with regional planning targets.

This regional autonomy results in the fact that, even though health promotion is considered part of public health and is entitled to receive at least $5 \%$ of the National Health Fund as part of the disease prevention core benefit package it only received $4.2 \%$ of the National Health Fund in 2013 (€4.9 billion) with wide regional variability (from 2.68\% in the Autonomous Province of Trento to $5.91 \%$ in the Valle d'Aosta Region) [26]. This means that this sector is underfunded by more or less $€ 1$ billion, $0.8 \%$ below the target established in the core benefit package defined at the national level [27].

\subsection{Financing major proyrammes/interventions in Health Promotion for Older Adults}

A specific system of financing for health promotion for the elderly is not in place in Italy. Nevertheless, health promotion funds are included in the health care budget as part of the national health fund, whose definition depends on an agreement between the Ministry of Health and the Ministry of the Economy and Finance [28].

The main programmes/interventions for HP4OP in the health sector are related to the regional implementation of the National Prevention Plan and to regional projects that address priority areas and targets of national importance under the Pact for Health ("Obiettivi di Piano"). About $€ 2$ billion of the 2014 National Health Fund were allocated to the regions that comply with these priority. According to Law 662/1996, priority should be given to "projects for the protection of maternal/child health, mental health, the health of the elderly as well as activities aimed at prevention, and in particular the prevention of hereditary 
The total standardised mortality rate in 2013 was equal to: 878.27 per 100,000 inhabitants, $1,112.82$ per 100,000 inhabitants for males and 717.7 per 100,000 inhabitants for females [18].

Mortality by main cause for the population $65+$

The standardised death rate for over 65 by all causes in 2013 was equal to 3,904.28 per 100,000 inhabitants, 4,933.7 per 100,000 in males and $3,246.73$ per 100,000 in females.

The main causes of death in Italy are ischemic heart diseases, which were responsible for more than 75,000 deaths in $2012(12.1 \%$ of total deaths); cerebrovascular diseases accounted for more than 61,000 deaths, equal to almost $10 \%$ of total deaths; other heart diseases killed around 48,000 people, (around $8 \%$ of total deaths); hypertension correlated diseases accounted for another $5 \%$ of deaths (more than 31,200 ). As a whole, heart related diseases represent the main cause of death in the country (more than $35 \%$ of deaths) and among the elderly as well [19].

Another important cause of death is represented by malignant tumours, in particular lung and respiratory cancers, which represent the $4^{\text {th }}$ main cause of death (more than 33,500 deaths, equal to $6 \%$ of the total deaths) and the $2^{\text {nd }}$ cause of death in men [20].

The number of deaths in the age class $65-84$ years (157,847 in men, 124,258 in women) accounted for about $50 \%$ of overall deaths. The top leading causes were ischemic heart diseases for males and cerebrovascular diseases for females. The malignant neoplasm of the trachea, bronchus and lungs was still the second leading cause in men. At older ages ( 85 years and over) apart from deaths due to heart and circulatory diseases, a remarkable proportion of deaths due to dementia and Alzheimer's was observed ( $7 \%$ of total deaths). It must be noted that in Italy, in 2013 , mortality rates related to dementias including Alzheimer's were: 34.28 and 38.23 for male and females, respectively, and 37.35 as a whole [20].

General classification of health status of older population according to "PASSI d'Argento" Surveillance System [17]:

- Elderly in good health and at low risk of illness (39\%);

- Elderly in good health but at risk of illness (24\%);

- Frail at risk of disability $(21 \%)$;

- Disable (16\%).

Prevalence of chronic diseases in the population $65+$ and the main health problems of older population

Prevalence of at least one chronic disease among people 65+: 64\% (33\% cardiovascular diseases, 25\% COPD; $20 \%$ diabetes; $13 \%$ cancer) [17] Prevalence of more than three chronic diseases among people 65+: $13 \%$ [17]

\section{DIABETES}

In 2012, over 3 million people declared they were affected by Diabetes, corresponding to around $5 \%$ of population. The prevalence of Diabetes is growing (from $3.9 \%$ in 2000 to $5 \%$ in 2012) due to the ageing population. In fact $80 \%$ of people affected by Diabetes are over 65 , affecting more than 1 out of 5 people over 75 [21].

\section{DEPRESSION}

Depression is present among older respondents to the "PASSI d'Argento" Surveillance at a rate of $21 \%$, higher in the age group 75 and over compared to $65-74$ ( $25 \%$ vs. $18 \%)$, with significant differences by gender ( $14 \%$ men vs. $26 \%$ women) [17].

The consumption of anti-depressive drugs in Italy has grown from 26.2 in 2004 to 39.3 DDD per 1,000 inhabitants per diem, showing on one hand an improved diagnostic capacity of GPs and on the other the use of such drugs as support for patients affected by oncological and chronicdegenerative diseases [22].

\section{Behavioural health risks}

\section{SMOKE}

There are 10.2 million smokers in Italy ( $60 \%$ males, $40 \%$ females) corresponding to around $19.5 \%$ of the population over 14 years old. The trend is in continuous decrease as well as the average number of smoked cigarettes, which decreased from 14.7 per day in 2001 to 12.1 per day in 2014. The proportion of smokers in the age class $60-64,65-74$, over 75 were $19 \%, 12.7$ and $4.7 \%$ respectively, men being more affected [23].

\section{ALCOHOL}

The prevalence of at risk alcohol consumers among the elderly (age class 65-74) in 2014 was $21 \%$ with $38 \%$ and $8.1 \%$ for males and females respectively [24].

\section{PHYSICAL ACTIVITY}

Among older respondents to the "PASSI d'Argento" Surveillance, $44 \%$ can be considered sedentary (in accordance with the Standard identified in the National Prevention Plan) [17].

\section{OBESITY}

In Italy, in 2014, about $36.2 \%$ of adults (over 18) were overweight (BMI $\geq 25 \mathrm{~kg} / \mathrm{m}^{2}$ ), with males being more affected (males $44.8 \%$ vs. females $28.2 \%$ ); $10.2 \%$ of people are obese (BMI $\geq 30 \mathrm{~kg} / \mathrm{m}^{2}$ ) with males at $10.8 \%$ and females at $9.7 \%$. So, a comprehensive $46.4 \%$ of the adult population is in a condition of excessive of weight.

The percentage of overweight and obese people rises with age. In fact, the percentage of overweight people grows from $14.9 \%$ in the age class $18-24$ to $46.5 \%$ in the age class $65-74$; likewise, the percentage of obese people rises from $2.4 \%$ to $15.7 \%$ in the same age classes [25].

Box 3. Health status of older population.

Source: Own work.

diseases". Since 2009, the Ministry of Health, in agreement with the State-Regions Conference, has identified, among others, at least two programmes dealing with HP4OP: chronicity management/frailty prevention and the promotion of physical activity among the elderly.

Furthermore, within this legislative framework, $€ 240$ million have been set aside for the implementation of the National Prevention Plan. In 2014, the Ministry of Health and the regions decided to allocate an additional $€ 200$ million of general national health funding for achieving the objectives of the National Prevention Plan. Careful observation of Regional Prevention Plans reveals that only a few projects can be classified solely as health promotion for the elderly, but a large number of projects aim to reduce chronic diseases and are consequently targeted at older people. Additionally, the programme 
Gaining Health, even if it is not specifically for older people, should be mentioned as an essential programme in this area. It is promoted and financed by the Ministry of Health and implemented by the National Institute of Health.

Some health promotion funds for the elderly derive from the social sector as well. As a whole, the Ministry of Labour and Social Policies and the Ministry of Internal Affairs are granted funds from general taxation in accordance with the "Documento di Economia e Finanze - DEF" (Document on economy and finance of the State) issued by the Ministry of Finance and the Budget Law issued by the Parliament, which authorises the government to collect and use public resources in its administrative activities [29, 30]. The two Ministries are in charge of funding national programmes in the field of social assistance for specific categories of the population such as non-self-sufficient older people (these programmes may or may not include HP4OP).

Specifically, the Ministry of Labour and Social Policies is responsible for the coordination of social services within the national healthcare system's infrastructure. The National Fund for Social Policies, with a budget of around $€ 300$ million, is distributed to Regional Governments upon the presentation of specific programmes and projects that may also include HP4OP [31]. Recently, through its Department of Social Cohesion, the Ministry of Internal Affairs has launched the national programme, "Care Services to Children and Frail Elderly" with the purpose of providing and implementing multidisciplinary services to frail elderly citizens in regions in southern Italy [32]. These funds are distributed in a given territory based on the projects presented by its municipalities. The presence of actions in the field of HP4OP is considered a main criterion for the assignment of funds.

Finally, some Regions decided to finance some projects using the structural funds provided by the European Union to promote the competitiveness of the regional economy and increase the social, economic and territorial cohesion. Regions assign these funds to the local industries according to a specific regional plan [33].

\section{Institutional analysis of health promotion interventions for older adults}

\subsection{Health Promotion for Older People performed by the Health Sector}

As a whole, HP4OP policies have been implemented in Italy since 1992 with the first national project being "Tutela della salute degli anziani" (protection of elderly's health), whose main objective was to improve "active life expectancy" in the elderly [34]. Preventive and promotional measures to facilitate access to health and social services, transportation and housing etc. for the elderly population first appeared in the National Plan 2001-2003 [35]. From 2011 onward, National Health Plans have taken into consideration the concepts of healthy and ac- tive ageing and fostered programmes to reduce chronic diseases, reduce inequalities and inequities and improve determinants of health. Integration between social and health institutions and programmes has become a starting point in initiating HP4OP programmes.

Currently HP4OP policy is based on the assumption that it is imperative to act not only through preventive and promotional health policies, but also by tackling all the extra-health determinants of health: social situation, income, mobility and civic participation, for example, are factors which significantly affect the state of health and autonomy of older people.

As a whole, the organisational structure of Public Health (PH) and Health Promotion (HP) services follows the overall structure of the National Health Service (SSN) since Public Health and health promotion are deeply interwoven with it. For this reason at the National Level the main institution responsible for $\mathrm{PH}$ and HP, including HP4OP, is the Ministry of Health, which is organised into General Directorates. In particular, the General Directorate for Disease Prevention (DG per la prevenzione sanitaria), the General Directorate for Health Care Planning (DG della Programmemazione Sanitaria), and the General Directorate for Hygiene and Safety of food and nutrition (DG per l'igiene e la sicurezza degli alimenti e la nutrizione) are the administrative structures dedicated to PH and HP [36]. National health promotion for the elderly strategies, programmes and projects are set and planned at this level even though a specific department for HP4OP, specifically healthy ageing, is not present. Regardless, since 2004 the National Centre for Disease Prevention and Control (CCM) has been the institution aimed at liaising between the Ministry of Health and regional governments in regard to surveillance, prevention and health emergency response. Over the years the CCM network has expanded its role to include designing evidence-based national strategies for disease prevention, health promotion and equity, providing operational support for project implementation and for identifying and disseminating best practices. Within this framework, the CCM can establish, with several million Euros per year, projects of national relevance [37].

The most important document in the field of health promotion and prevention is the National Prevention Plan (NPP), issued as part of the National Health Plan (NHP) [38].

Public health and health promotion policies, including HP4OP, as outlined in the NPP, are implemented by the regions and their Regional Health Departments through the Regional Prevention Plan (RPP); it must be noted that Regional Health Departments coordinate both health and social care through a Standing Conference for Regional Health and Social Care Planning [36].

At the local level, health promotion and prevention of the population is ensured by the ASLs. GPs represent the main actors in terms of HP4OP due to their direct relationships with patients and since, apart from diagnosis and treatment, their main functions also include: patient education in terms of social, cultural and environmental behaviours that might influence health promotion and 
prevention, health status and responsibility for information concerning district services. Apart from GPs, districts are also responsible for integrated home care delivery that includes the activity of several professionals (such as GPs, specialists, nurses, social assistants) and they enable advocacy actions towards the elderly by enhancing and sustaining programmes and behaviours in the context of health promotion and prevention [39]. Finally, another important role is played by the Departments of Prevention, which are directly or indirectly accountable for Influenza and Pneumococcal vaccinations as well as specific screening programmes for the elderly (together with GPs) and also foster patients to improve lifestyle, diet and social inclusion [40].

\subsubsection{Key health promotion strategies/programmes for the elderly within the health sector}

A specific national plan on HP4OP is not in place in Italy. Nevertheless, starting from 2005, the first National Prevention Plan was issued by the Ministry of Health and health promotion was included in it. Specific areas of intervention were identified in this plan and HP4OP was one of the areas considered for funding. The National Prevention Plan is implemented through the Regional Prevention Plan, taking into account the regions' needs and priorities [37]. In 2007, the National Prevention Plan, following an intersectoral approach, launched the National Programme "Gaining Health" (Guadagnare Salute), with the aim of modifying the main risk factors for the population, and, as for the elderly, to reduce the burden of chronic diseases by tackling risk factors, inadequate behaviour and the extra-health determinants of health. This programme involves a great number of stakeholders and its main objective is to develop and communicate widespread policies in order to: promote mobility and physical activity of people (transportation and urban green areas); support fruit and vegetable consumption; reduce the concentration of salt, sugar and fat in food; reduce the share of high-caloric foods in the diet; discourage smoking and alcohol abuse [41].

Additional resource for the implementation of HP4OP have been assigned by the CCM since 2007: i.e. in 2009 the CCM network funded a project aimed at testing screening and comprehensive assessment procedures for frail elderly citizens in Tuscany (Central Italy) in the model of interventions to prevent disability. Other project about frailty and its prevention have been carried out in Emilia Romagna, Liguria, Lombardia, Puglia, Veneto. This topic is very relevant and challenging and requires further investment to prevent frailty, to postpone its onset or to slow its progression as well as to measure and manage frailty in community-dwelling older adults.

In order to programme a national strategy capable of preventing the elderly from getting ill or losing their autonomy, the Ministry of Health sponsored a specific Surveillance System for the elderly called "PASSI d'Argento" which is carried out by the National Institute of Health (ISS) [17]. This monitoring system is capable of identifying the major modifiable determinants of health in elderly citizens over 65 so that the information it yields can be used to implement more appropriate and effective actions in the field of HP4OP. In fact, "PASSI d'Argento" might become the basis for good health promotion planning and the drafting of future National Prevention Plans. Consequently, Regional Plans concerning the socio-health conditions of the elderly might also use its data in order to better organise and design health promotion programmes and plans at the local level.

Other Programmes worth mentioning are: the National Operative Plan Against Sudden Excessive Heat called "Ondate di Calore" whose objective is to prepare elderly people, especially those with limited thermoregulation capacity or who are frail, to face excessive heat and high environmental temperatures [42]. This plan is issued by the Ministry of Health in collaboration with the Centre for Prevention and Control of Diseases (CCM) in order to reduce the impact of excessive heat on health; it is implemented at the local level by the ASLs with the support of General Practitioners (GPs) that identify frail elderly citizens and provide proper information and education on the issue. The program was implemented with the collaboration of the National Civil Protection (Protezione Civile) and several non-for profit organizations [43].

\subsubsection{Cooperation within and between sectors}

At the national level, as stated above, the Ministry of Health, following an intersectoral approach, promoted by Decree N²29/1999, launched in 2007 the National Programme "Gaining Health", which involves a great number of organisations from different sectors, including ministries, governmental agencies, the educational sector, environmental agencies and police forces etc. in order to disseminate health promotion policies among the population.

According to Decrees 229/1999 [5] and 328/2000 [7], the integration between the health and social sectors is managed by the ASLs, through a functional unit called the District (Distretto Socio Sanitario), and the Municipalities, through dedicated units. In particular, the ASLs provide the Programme of Territorial Activities (PAT), and Municipalities define social care plans called "Piani di Zona" - (Zonal Plans). These plans are combined into a wider Local Action Plan (PAL) that describes the provision of health and social services delivery at the local level, including the role and participation of the Voluntary sector and NGOs, which play a fundamental role in the effective implementation of projects, actions and policies regarding HP4OP.

In terms of HP4OP at the local level, an important role is played by the Multi-Dimensional Evaluation Unit created by the district within a given ASL territory. In addition to medical assessment, patients get in contact with this multidisciplinary team that takes care of both social and health needs, suggests to patients how to better control their illness and promotes healthy lifestyles and behaviours. The implementation of innovative and reliable instruments for multi-dimensional evaluation was developed in a specific project within the Regional Prevention 
Plan of the Marche Region. Another strategy was developed in recent years in the Veneto region; with the application of the DGR 41 of 18/01/2011, a new organisation of primary care, based on Functional Territorial Aggregations (Aggregazioni Funzionali Territoriali), was launched together with the so called Integrated Group Medicine (Medicina di Gruppo Integrata). This new primary care model consists in the integration of resources, including GPs, nurses and administrative personnel from the district and social assistants and other administrative personnel from Municipalities, with the aim of creating a wider network capable of improving health promotion and prevention as well as the integration of social services and health care. Regardless, it should be highlighted that implementation of both the above-mentioned models is very different across the regions, without national standards.

In the context of specific projects, such as those realised within the framework of the CCM network, the ASL could involve local universities and regional research centres.

Finally, the most recent National Prevention Plan identified the workplace as one of the most effective settings for Health Promotion. In this framework, the ASL of Modena is carrying out a pilot project that involves the department of prevention, voluntary occupational health physicians and social partners (employer representative associations and trade unions). Italian companies, with quite a high mean age of employees, have strong internal commitment to target workplace health promotion to older people.

\subsubsection{Identification of the main limitations and barriers in health sector involvement in health promotion programmes for the elderly}

One of the main limitations in the dissemination of HP4OP programmes is rooted in the lack of a welldesigned national strategy in this field: specific HP4OP strategies and funds are not clearly defined and only portions of them are considered under the umbrella of disease prevention.

Another barrier is the fragmentation of policies at the regional level due to the different distribution of district functions among regions: in some regions, districts are in charge of both production and commissioning of services, in others the function of commissioning is kept within district control while production of services is delegated to a third party; finally, in regions like Tuscany, the two functions are managed together by districts and Municipalities, which share responsibilities. This last model ensures that a third sector, involving the voluntary sector and NGOs, participates in decisions along with ASLs and Municipalities. These differences in terms of district organisation might be responsible for different outcomes in terms of the implementation of actions, projects and programmes of health promotion for the elderly. Furthermore, health promotion funds, plans and activities at the local level depend on the General Director's choices that, indirectly, reflect those of the regional government that appointed him; the DG is appointed by the Regional Government (Giunta regionale), a political body, without public competition to select the candidate. Finally, another barrier to the dissemination of HP4OP derives from an insufficient knowledge of district health and social services by health professionals and GPs, as well as from the fact that all the stakeholders do not share a clear interpretation of health promotion.

\subsection{Social Assistance Sector}

The role of the Social Assistance System is still very important in Italy despite the health system reform of 1978 that initiated the shift from a Bismark to a Beveridge model. Currently, at the national level, the Ministry of Labour and Social Policies and the Ministry of Internal Affairs contribute to the improvement of the population's health status through the definition of social assistance programmes that act directly or indirectly on health, behaviours, lifestyles, social cohesion, mobility and also health promotion for specific groups of the population, such as the elderly. The integration between social and healthcare needs is realised at the regional and, mostly, local levels through the definition and implementation of specific strategic plans. Therefore, Regional Governments and Municipalities have a fundamental role in the implementation of both social and health promotion actions.

The most important national fund granted to Regional Governments for the development of an integrated network of social services and interventions is the National Fund for Social Policies issued by the Ministry of Labour and Social Policies in accordance with Law 328/2000 [7]. Funds for Regional Governments are provided if regional social care plans are in accordance with the abovementioned national programmes and specific criteria defined by law. Regional social care plans take into consideration the social service and health care needs of the elderly population living in the area and present policies and programmes, including those regarding health promotion for the elderly, proposed by the Municipalities. The local level is indeed responsible for the organisation and implementation of actions regarding social welfare and health promotion for the elderly in the field. The performance of Municipalities is then evaluated in order to obtain the funds. Besides the Ministry of Labour and Social Affairs, the Ministry of Internal Affairs as well as the Department for Family Policies of the Presidency of the Council of Ministers might access funds from the European Social Fund (ESF) for promoting policies in the field of health promotion, social inclusion and social assistance for the elderly. These funds finance specific programmes and activities defined by European policies and carried out at national level mostly by Provinces and Municipalities but also by NGOs and other organisations that act as organisers and promoters.

It must be noted that access to social care services and interventions is allowed primarily to all citizens with low incomes as certified by the value of their Equivalent Economic Situation Indicator (ISEE), which takes into consideration: income, assets and family characteristics. 


\subsubsection{Key health promotion strategies/programmes for the elderly within the Social Assistance Sector}

The public policy and funding framework for HP and social assistance for the elderly has not changed significantly in the last decade despite the increase in care needs. The coverage rates of public services are almost equal to those of ten years ago and are mainly based on the granting of a carer's allowance for those caring for frail elderly people. Nevertheless, in Italy there are several programmes in place aimed at health promotion towards the elderly carried out within the social assistance sector, even though they are not always structured in a well-defined strategic policy. Furthermore, the information regarding these programmes are not easily accessible, usually in Italian and without data regarding the real impact of the initiatives nor regarding indicators of the process.

The national programme "Staffetta Generazionale" (Generational Relay) is a project financed by the Minister of Labour and Social Affairs and implemented by Regions and Autonomous Provinces through the assistance of "Italia Lavoro" (Work Italy) in the framework of "Welfare to Work", the re-employment policies for 2012-2014. The project's aim is to encourage companies to hire a young worker while converting the full-time job of an older worker into a part-time job, promoting intergenerational exchange and maintaining lifetime employment of older workers, thus avoiding social isolation. The Minister of Labour and Social Affairs finances the programme to the cost of 40,285,961 euro [44].

During the European Year of Active Ageing in 2012, the Department for Family Policies was in charge of coordinating all the initiatives among its plans of activity in Italy. So, in 2012, it funded (with 1.5 million euros) 47 projects to spread greater knowledge on issues related to Active Ageing in Italy [45]. The financed projects were promoted and organised by the Provinces, Municipalities, NGOs and other organisations. For example, the project "The Pink and Grey" aims at promoting intergenerational exchange and creating a network among elderly women, who already hold top positions in enterprises, and young women early in their careers so that cases of successful women become examples for other women to learn from and be encouraged by. Another example is "Argento Vivo" (Quicksilver), a project promoted by the Municipality of Castiglione Fiorentino that aims at facilitating voluntary activity related to the transfer of knowledge between the elderly and young people on 5 social issues [46].

Several Regions are also using European resources from the European Regional Development Fund to promote research and development projects aimed at ensuring active and healthy ageing [47].

Another health promotion strategy for the elderly involves a wider implementation and strengthening of social home care, that should be integrated with the home care provided by the health sector. This requires the involvement of several professionals with the aim of improving quality of life, guaranteeing better food con- sumption and avoiding the isolation of elderly people. In this respect, the Department of Social Cohesion of the Ministry of Internal Affairs launched (and financed) the national programme of "Care Services to Children and the Elderly Frail" with the purpose of providing and implementing multidisciplinary services to frail elderly people in regions of southern Italy [48].

\subsubsection{Cooperation within and between sectors}

The cooperation of the different level of SAS is well structured and has already been described. On the contrary, the cooperation with other sectors and institutions in health promotion programmes for the elderly is not comprehensively structured and is mainly entrusted to single programmes and projects, which are often carried out at the local level.

As a whole, according to Dlgs. 229/1999 [5] and Dlgs $328 / 2000$ [7] the integration between social services and health care is managed at the local level through the participation of the Municipalities (and their representatives) in the definition of local plans developed by the districts of the ASLs and the Municipalities. It must be noted that districts, despite being functional institutions of the ASLs, are eventually granted separate budgets within their ASLs and might also account for specific funds provided by the social sector, namely the Ministry of Labour and Social Policies.

The social, health and voluntary sectors can collaborate on specific projects, in favourable circumstances and settings. Good cooperation between different sectors depends on institutions like the family and the religious community. In fact, the lack of a structured and widespread network of services for the elderly in Italy is compensated for by families that organise, deliver and, in some cases, finance care, social assistance and health promotion activities. Because of this, the Italian national care and social assistance scheme has been labelled "familist", along with other countries of southern Europe [49].

A very interesting example of cooperation is represented by "Happy Ageing," the Italian alliance for active ageing, founded in 2014 to promote policies and programmes to protect and promote the health of the elderly in Italy. The alliance is composed of scientific societies (like the Italian Society of Hygiene and the Italian Society of Geriatrics and Gerontology), several trade unions and older representatives. The aims of the Happy Ageing alliance are advocacy for HP4OP at the national level and the collection of all the best practices in the field of elderly wellness [50]. Other interesting examples can be found in the project "Viva gli Anziani," in the "Alzheimer's Cafè" and in the initiative "Give Memory" of the Forum of Family Associations. "Viva gli anziani" (Long Live the Elderly!) is a project promoted and organised by the Sant'Egidio Community, in cooperation with the Italian Ministry of Health and the municipality of Rome, which aims at fighting the social isolation of the elderly by creating a network between older people to prevent critical events [43]. It is inter- 
esting to underline that the preliminary results of this project have been recently published: Marazzi et al have shown its capacity to reduce the over-74 hospitalization rate, the use of Long Term Care and the cost of services used by the studied population [51]. The "Alzheimer's Cafè" is a place where patients with dementia and their relatives can share information, exchange their experiences and support each other. These cafès are organised by one or more municipalities in collaboration with local cooperatives and associations as well as the ASL [52]. "Give Memory" (Donare Memoria) from the Forum of Family Associations is an initiative that aims at shifting the role of elderly people from "social cost" to "social resource" by encouraging intergenerational exchange. Older people's memories are shared with young people so that the elderly have an active role and wider social inclusion [53].

\subsubsection{Identification of the main limitations and barriers in Social Assistance Sector involvement in health promotion programmes for the elderly}

Despite the social service and health promotion issues related to the elderly which have entered the public arena since the beginning of the new millennium, they have not been tackled adequately and there is a lack of definition of the Basic Levels of Social Assistance at the national level as well as a strong heterogeneity of regional laws that regulate the administration of integrated social services and health care.

Moreover, the missions defined in the National Budget Law and the programmes proposed by the Ministries of Labour and Social Policies and the Ministry of Internal Affairs are mostly geared to assistance, in particular care-assistance, rather than health promotion and prevention for the elderly. Although several proposals have been advanced by all political parties to implement a health promotion and prevention system for the elderly as well as a system for the needy elderly, most of the reforms adopted by the Italian government have focused mainly on the pension system and, only partially on setting health promotion policies [54].

Additionally, there are modest endowments of public services to support frail older people in Italy but public interventions are initiated mainly when people are in situations of serious dependence and, in any case, these interventions are focused on provision of a carer's allowance, the payment of which is not combined with any mechanism capable of ensuring that it is used properly. It must be noted that when the economic situation of a family is not so compromised, the carer's allowance is not guaranteed such that families have to bear the costs of care.

Another issue is that regionalisation of services has led to the jeopardisation of social care activities towards the elderly throughout the country, with huge differences in terms of allocation of welfare resources. This might imply a general inadequacy of the regional regulatory framework to produce balanced subsystems at the local level where fragmentation is actually very evident. Basically sub-regional differentiation in social assistance is not due to a different structure of needs, but rather to a dissimilar intervention capacity [55].

As a whole, the lack of a comprehensive national and regional strategy in terms of health promotion for the elderly within social care is one of the factors that have led to the consolidation of a massive private care market. In fact, the needs of elderly people have been covered mostly by low-cost private services, such as those offered by private caregivers, whose focus is on care and not on health promotion and prevention [56].

\subsection{Regional/Local Self-Government}

Regional and Local governments play an essential role within the Health and Social Assistance Sectors that has already been described in the previous sections. Since the 2001 Constitutional Reform, regions have shared planning and financing responsibilities with the central government in the form of the permanent State-Regions Conference. Furthermore, regional governments are in charge of the management of ASLs and Hospitals by defining their geographical boundaries, allocating resources to them, and appointing their directors. Consequentially, the 21 regional governments (19 regions and 2 autonomous provinces) are fully entitled to manage their own regional health and social system according to their specific needs and demand. That entailed the creation of different Regional Health and Social Systems with relevant implications in Social that will be discussed in this section, together with the role and peculiarity of the local governments.

\subsubsection{Key health promotion strategies/programmes for the elderly attributed to different Regional and Local authorities}

Key health promotion strategies for the elderly at the regional level depend on both the health and social sectors. The executive functions of the regional governments in health care, mainly carried out through the Regional Departments of Health, include the definition of a three-year Regional Health Plan. Activities and projects regarding prevention and health promotion as a whole, including health promotion for the elderly, are described in the Regional Prevention Plan. As stated before, each regional authority has the autonomy to run its own regional health system according to its specific needs and demand. Therefore some regions might decide to invest more in health promotion for the elderly programmes and projects. On the other hand, the presence of a specific programme for health promotion for the elderly within the regional prevention plan is not compulsory. Below are some examples of programmes within different regional prevention plans specifically targeting HP for the elderly:

- the promotion of physical activity (i.e. the Project "Colori in Movimento" (Colours in Movement), implemented by the Abruzzo Region; the project "Anziani in Cammino" (elderly on the way), implemented by the Umbria Region; the projects "Gente in Gamba 
+65" and "Attività Fisica Adattata" (AFA), implemented by the Marche and Liguria Regions);

- the promotion of healthy eating habits (i.e. the Project "Colori in Movimento" (Colours in Movement), implemented by the Abruzzo Region; a project to improve food delivery in nursing homes, implemented by the Piemonte Region;

- the prevention of falls and trauma (i.e. a project to avoid domestic falls, implemented in several Regions (Calabria, Emilia Romagna, Liguria, etc); the project "Ossi duri si diventa" implemented by the Marche Region and aimed at training caregivers of elderly people).

For social assistance, a Social Regional Plan is approved by the Regional Council in accordance with Law 328/2000 [7]. The social plan defines an integrated system of social interventions implemented with the help of Municipalities, NGOs, the voluntary sector and the third sector as a whole. In some regions, integrated social-health plans have been proposed with the objective of removing the psychosocial hardship and marginalization of some citizens, thus transforming them into active actors in the social and health system. Furthermore, in accordance with regional autonomy and within the framework of the national prevention plan, some legislative interventions promote the elderly's involvement in social and public life as a fundamental resource: for example, in the Autonomous Province of Trento, with Regional Law n ${ }^{\circ} 11 / 2008$, elderly people are invited to join the voluntary service to transfer their knowledge and experience to younger generations. Similarly, in the Umbria region, Regional Law $n^{\circ} 14$ of September the $27^{\text {th }} 2012$, has promoted active ageing as a key strategy to bring the elderly into social action and participation.

\subsubsection{Cooperation within and between regional and self-yovernments in the sphere of health promotion programmes for the elderly}

Regional Health Departments are responsible for the coordination of health and social care through a Standing Conference for Regional Health and Social Care Planning. Nevertheless, most of activities and projects for the elderly are developed and implemented at the local level by ASLs, Municipalities and Communes. When health promotion programmes for the elderly are included into the Regional Health or Prevention Plans they should be implemented at the local level by Local Action Plans. Cooperation with the social sector depends on the degree of commitment of the Regional and Local Department for Social Policies and their capacity to work together with districts of LHAs and third sector actors. Integration between NGOs, the health sector and the voluntary sector, etc. depends mostly on the Zonal programmes and plans established by Municipalities and ASLs in accordance with the other stakeholders at the local level. As an example, the Marche Region has recently signed an agreement with the UISP (Italian Union for Sport for All) to put the Department of Prevention in contact with local sports organisations to improve physi- cal activity targeted based on age (children and teens, adults and seniors) [57].

In the context of specific projects, most of the regions involve local universities and regional research centres. For example, in the Marche Region there is the only one IRCCS (Research and Care Institute aimed at Scientific Development) specialised in geriatrics and gerontology, the National Institute for Rest and Care of Elders (IRCCS-INRCA). The IRCCS-INRCA is often involved in several European and national projects aimed at assessing the effectiveness of HP4OP strategies, such as:

- The SPRINT-T project, aimed at preventing sarcopenia and disability through a complex intervention that combines physical activity and nutrition [58];

- The Up-Tech project tested, in more than 500 families of people suffering from Alzheimer's, the effectiveness of an intervention of case-management and home automation;

- Several European projects aimed at developing new technologies for the quality of life of the elderly at home (SMART HOUSE and ROBOT-ERA Projects).

An innovative method of cooperation in the field of Social was launched in 2012 by the European Innovation Partnership on Active and Healthy Ageing through the identification of "reference sites": coalitions of regions, cities, integrated hospitals or care organisations that aim to provide a comprehensive, innovation-based approach to active and healthy ageing - and that provide concrete examples of their positive impact. Reference sites demonstrate synergy between different actions and breakthrough solutions within a short time frame, as well as the added value of a holistic approach. To date, all 5 Italian Reference Sites are regions (Liguria, Campania, Emilia Romagna, Friuli Venezia Giulia and Piemonte) and several regions submitted their application for the new call in 2016 [59].

\subsubsection{Presentation and short description of examples and good practices of health promotion programmes for the elderly implemented at the regional and local levels}

The first example of good practice of Social programmes can be found in the Network "Italia Longeva," created by the Ministry of Health, the Marche Region and IRCCS-INRCA. The network enhances the active role of elderly people in society, considering them a resource and not a cost: elderly people's experience and knowledge are used in order to create new social and health services (that the elderly themselves will use) through the implementation of concepts such as techno-assistance, domotics, tele-medicine and tele-monitoring. The idea is to disseminate new modalities of care, particularly home care, with the aim of guaranteeing the elderly greater autonomy, a better quality of life and, at the same time, reducing healthcare costs through the development and the implementation of new technologies. A similar project in the field of healthy ageing worth mentioning is the OPLON (OPportunities for active and healthy LONgevity) project, whose objective is to prevent the 
elderly from becoming frail through the use of high technology solutions that support the creation of "smart health communities" in defined territories. This project is sponsored by the Universities of Bologna and Bari, the Polytechnic of Torino and other national enterprises [60].

The project "Orti Urbani" (urban gardens), a project promoted and organised by the NGO "Animo Onlus," in cooperation with the municipality of Cerveteri, aims at involving older people in the cultivation of land and inter-generational knowledge transfer [61]. This initiative is very popular in Italy and a great number of Italian Municipalities provide free plots of land to older people to promote activities that encourage autonomy and physical and mental well-being, socialisation, participation in community life, initiative and the self-organisation of citizens.

Interesting projects are also being developed in the Liguria region, where Law $n^{\circ} 48$ of November 2009 favoured projects of active ageing and the promotion of health and social actions towards the elderly such as: lifelong education programmes, sports and healthy lifestyle programmes, participation of the elderly into the voluntary sector and the promotion of the social inclusion of elderly people. An interesting project called "Immigration as a Social Resource Rather than a Source of Fear" (AUSER) aimed at overcoming older people's fear and prejudice against immigrants by setting up meetings between older people and their families and the families of immigrants as a means of overcoming stereotypes and building cultural awareness and exchange. Another initiative worth mentioning is the project "Improving Quality of Life in the Third Age through New Technology," whose objective is to train older people to become "computer literate" and familiar with technology. Thanks to this initiative, older people in the Liguria region have approached the Internet and computer technology and their quality of life has improved thanks to their ability to contact the Public Administration through online services.

The Liguria region is also one of the 5 Italian regional sites of the European Innovation Partnership on Active and Healthy Ageing, which supports projects which improve cognitive functioning "i.e., Memory Training" and physical activity. The other "Reference Sites" presented programmes to prevent and reduce functional decline and frailty among older people (Campania), to use information and communication technology in healthcare (Campania, Emilia Romagna), to improve the quality of life for the elderly population with visual disabilities (Friuli Venezia Giulia) and to train health care professionals in providing a proactive management model of care for chronic diseases (Piemonte).

Some other interesting projects include the implementation of the WHO "Age Friendly City" concept in the city of Udine (whose project turned into a model to be implemented in other cities) and the project Pro Senectute, developed in Omegna, a little town in the Piemonte region, where people over 65 were involved in music and cuisine courses, plant cultivation and healthy diet sessions, etc. and showed a better life expectancy without disabilities [62]. The "Age-Friendly City" is a WHO project that involves 35 cities in 22 Countries all around the world, with the collaboration of governmental, nongovernmental and academic groups. The project is aimed at developing or implementing policies, services such as outdoors spaces and transportation, settings and structures to support and enable people to age actively. Udine, a city in the Friuli Venezia-Giulia region with a population of almost 100,000 inhabitants, was one of the 35 "Age-friendly Cities", the first and only one in Italy. The activity of the project, undertaken by the Municipality of Udine, included the creation of new opportunities for intersectoral and inter-generational work; the involvement of the elderly community in social activities; matching the distribution of the elderly in the city to the provision of public, health and social services offered at the local level; recording the experiences and needs of older people through a consultative process with citizens, caregivers and providers of services to discover the existing "age-friendly" urban features as well as the barriers to active ageing; and promoting opportunities for older people to remain physically, mentally and socially active through activities at the local level. Additionally, the initiatives of the project led to the implementation of food and mobility policies oriented towards the elderly: involving groups of about 15-20 older people who meet at a station point for a walk of $10-15 \mathrm{~km}$ a day in a green park; providing elderly people with the opportunity to participate in a cycle of seminars and cooking workshops; creating occasions for socialisation and gathering people of different ages. The Municipality of Udine financed all the activities implemented in the frame of the project at the cost of about 100,000 euros $[63,64]$.

\subsubsection{Identification of the main limitations and barriers in planning and implementing health promotion proyrammes for the elderly}

The main barriers to planning health promotion programmes for the elderly derive from the lack of specific national and regional regulations in this field. The National Health Plan does not define mandatory funds for health promotion for the elderly and neither does the National Prevention Plan include Social as a specific issue to tackle. The same is true at the regional level with regional health and prevention plans that may or may not include Social as a main topic to address.

As for the implementation of Social projects, this mostly depends on the performance of underfinanced districts or municipal budgets. Furthermore, health, social and voluntary sector professionals are usually oriented towards care and assistance instead of promotion.

Finally, it must be underlined that in a context of limited resources, health promotion for the elderly actions and projects are not seen as priorities by decision makers who prefer results in the short term, sometimes demonstrating a lack of vision.

\section{Summary and conclusions}

Health Promotion for the elderly in Italy is carried on mainly by the Ministry of Health within the framework of the National Health System through the part 
of National Health Fund dedicated to disease prevention. Nevertheless, funds and resources also derive from the Ministry of Labour and Social Policies through the National Social Fund and, for specific issues, from the Ministry of Internal Affairs. Moreover, European funds might also be used for this purpose.

In general, HP4OP is considered within the context of the National Prevention Plan, which is issued in accordance with the National Health Plan, and receives funds only if regional governments assign funds to it. This happens since each region, according to the newest reforms of the healthcare system and constitutional law, is basically free to manage its own health care system according to its specific needs. Regions have to guarantee core benefit packages established at the national level, but are independent in their choices as to financing specific priorities and programmes in the health sector as well as in terms of labour and social policies.

In the health sector, part of the funds dedicated to prevention should also cover health promotion, including that for the elderly. Resources are assigned to the operative unit of the local health authorities called Districts. As for the social sector, a compulsory fund for HP4OP is not in place nationwide. Regional governments perform territorial needs analysis and propose regional bids in order to address funds to Municipalities and other Entities acting in the territory and HP4OP receives public resources when it is considered to be of top priority or at least an issue to tackle at the regional/local level. For this reason, projects and programmes are developed heterogeneously among regions.

The integration of both social and health actions in terms of HP4OP is realised at the local level where the ASLs and the Municipalities draw the Local Territorial Plan and the Zonal Plan for health care and social care respectively. Both plans are taken into consideration in a wider Local Action Plan that determines and describes how to implement integrated social services and health care projects and actions at the local level and the actors involved in doing so, such as the district, health professionals, NGOs, the voluntary sector, educational entities etc.

As a whole, the main actors in the implementation of HP4OP actions are GPs and other health professionals together with voluntary service staff. Nevertheless an important role is also played by families and religious communities, both significant institutions throughout the country. These actors are notably historically linked and achieve impressive results and, with the help of the municipalities and the ASLs, are capable of organising structured and integrated projects of health promotion for the elderly at the local level.

In general, a strong evolution in terms of policies towards HP4OP has taken place in Italy in the last twenty years: elderly people have passed from merely being cured and assisted, viewed only as sick, unproductive and passive subjects, to being the centre of new policies according to which governments should act not only through preventive and promotional health policies, but also to tackle all the extra-health determinants of health such as social situation, income, mobility, civic participation, etc. All are factors which significantly affect the state of health and autonomy of older people. Interestingly, just on 9 June 2016, the first parliamentary intergroup "Active ageing" was founded to perform advocacy for older citizens and to stimulate the action of the government towards initiatives to develop policies in favour of active and healthy ageing in Italy. It will aim to promptly receive the recommendations from the European Commission, including the target of an increase of two years of healthy life expectancy of people by 2020 in the 28 member countries. The deputies and senators who have decided to join this group will promote bills, questions and motions to develop a concrete solidarity between generations, ensure active ageing and healthy citizens and to meet the needs of millions of families who are caring for an elderly relative.

The main barriers to the realisation of such policies are due to the lack of specific national and regional health plans, regulations and orientations in the HP4OP field. Moreover, in terms of social care, most actions and projects are also addressed to care-assistance rather than health promotion and prevention for the elderly. This general state of the actual social policies, together with the fragmentation of policies at the regional levels, constitutes a limit to the implementation of homogeneous HP4OP strategies and programmes. Another limitation is presented by the absence of data about the process and/or the impact of activities dedicated to promoting Active and Healthy Ageing. Last but not least importantly, field implementation of HP4OP projects mostly depends on the performance of underfinanced districts or municipal budgets and not all GPs, nurses or other health professionals and volunteers interpret the term "health promotion" in the same way.

In conclusion, even if Italy is one of the countries where people live the longest, the $65+$ age group is burdened with chronic diseases and unhealthy lifestyle choices, and more than $40 \%$ of older people are at risk of illness or infirmity. HP4OP has generally been considered less important than care assistance and most reforms have focused on the pension system rather than HP policies. Effective HP4OP policies and programmes should be enhanced to reduce the problem of non-communicable diseases and to improve the quality of life for the ageing population. More attention should be given to multi-factorial and multi-disciplinary programmes that use a variety of strategies to target multiple domains (for example: social and work participation, physical activity, healthy eating) and encourage individuals and communities to change their lifestyles and take more responsibility for their health. Regionalisation has jeopardised health and social care activities targeted at the elderly as there are vast regional differences in terms of the allocation and use of welfare resources. A stronger stewardship role is required at the national level to develop integrated social and health promotion for the elderly sustained, by both social service and health care funds. Finally, investments in training and capacity building are essential to improve knowledge and attitudes of different public health professionals and other actors involved in HP4OP. 


\section{References}

1. Sitko S.J., Kowalska-Bobko I., Mokrzycka A. et al., Institutional analysis of health promotion for older people in Europe-concept and research tool, "BMC Health Services Research” 2016;16 (Suppl. 5): 327. doi:10.1186/s12913016-1516-1.

2. Ferrè F., de Belvis A.G., Valerio L., Longhi S., Lazzari A., Fattore G., Ricciardi W., Maresso A., Health Systems in Transition: Italy HiT 2014, http://www.euro.who.int/en/ about-us/partners/observatory/publications/health-systemreviews-hits/full-list-of-country-hits/italy-hit-2014; accessed: 16.05. 2016

3. Decreto Legislativo 30 dicembre 1992, n. 502. "Riordino della disciplina in materia sanitaria, a norma dell'articolo 1 della L. 23 ottobre 1992, n. 421".

4. Decreto Legislativo 7 dicembre 1993, n. 517. "Modificazioni al decreto legislativo 30 dicembre 1992, n. 502, recante riordino della disciplina in materia sanitaria, a norma dell'articolo 1 della legge 23 ottobre 1992, n. 421".

5. Decreto Legislativo 19 giugno 1999, n. 229. "Norme per la razionalizzazione del Servizio sanitario nazionale, a norma dell'articolo 1 della legge 30 novembre 1998, n. 419".

6. Legge costituzionale 18 ottobre 2001, n. 3. "Modifiche al titolo V della parte seconda della Costituzione".

7. Legge 8 novembre 2000 , n. 328 . "Legge quadro per la realizzazione del sistema integrato di interventi e servizi sociali”.

8. Conferenza Permanente per i rapporti tra lo Stato, le Regioni e le Province Autonome di Trento e Bolzano, Patto per la Salute 2014-2016. 10 jul 2014, http://www.statoregioni. it/Documenti/DOC_044351_82\%20CSR\%20PUNTO\%20 \%2016\%20ODG.pdf; accessed: 10.05.2016.

9. Ministero della Salute, Piano Nazionale della Prevenzione 2014-2018, http://www.salute.gov.it/imgs/C_17_pubblicazioni_2285_allegato.pdf; accessed: 16.05.2016.

10. Decreto Legislativo 18 febbraio 2000, n. 56. "Disposizioni in materia di federalismo fiscale, a norma dell'articolo 10 della legge 13 maggio 1999, n. 133".

11. World Bank, Health expenditure per capita 2014, http:// data.worldbank.org/indicator/SH.XPD.PCAP; accessed: 16.05 .2016

12. OECD 2015, Total expenditure on health per capita, http:// www.oecd-ilibrary.org/social-issues-migration-health/totalexpenditure-on-health-per-capita_20758480-table2; accessed: 16.05.2016.

13. WHO 2015, Global Health Expenditure Database, http:// apps.who.int/nha/database/ViewData/Indicators/en; accessed: 15.06.2016.

14. OECD, Total expenditure on health. 2015, http://www.oecd-ilibrary.org/social-issues-migration-health/total-expenditure-on-health_20758480-table1; accessed: 13.05.2016.

15. OECD, Health Statistics 2015, https://www.oecd.org/els/ health-systems/Country-Note-ITALY-OECD-Health-Statistics-2015.pdf; accessed: 16.05.2016.

16. EUROSTAT, http://appsso.eurostat.ec.europa.eu/nui/submitViewTableAction.do, accessed: 13.06.2016.

17. Gruppo Tecnico di Coordinamento del Sistema di Sorveglianza PASSI d'Argento, Luzi P. (ed.), Sperimentazione PASSI d'Argento (Progressi delle Aziende Sanitarie per la Salute in Italia): verso un sistema nazionale di sorveglianza della popolazione ultra64enne, Istituto Superiore di Sanità, Roma 2013. Rapporti ISTISAN 13/9, http://www.epicentro. iss.it/passi-argento/; accessed: 13.06.2016.

18. Osservatorio Nazionale Sulla Salute delle Regioni Italiane, Rapporto Osservasalute 2015. Prex, 2015, www.osservasalute.it; accessed: 13.06.2016.

19. ISTAT, Leading causes of death in Italy. ISTAT 2014, http:// www.istat.it/en/archive/140877; accessed: 13.06.2016.

20. ISTAT, Le principali cause di morte in Italia 2014 (dati 2012), http://www.istat.it/it/archivio/140871; accessed: 13.06.2016.

21. ISTAT, Il diabete in Italia. ISTAT 2014, http://www.istat.it/ it/archivio/71090; accessed: 13.06.2016.

22. OsMed. AIFA, L'uso dei farmaci in Italia. Rapporto Nazionale. Anno 2014.

23. Osservatorio Nazionale Sulla Salute delle Regioni Italiane, Fattori di rischio e stili di vita, in: Rapporto osservasalute 2016. Prex, 2016, www.osservasalute.it; accessed: 13.06.2016.

24. Osservatorio Nazionale Sulla Salute delle Regioni Italiane, Alcol, in: Rapporto osservasalute 2016. Prex, 2016, www. osservasalute.it; accessed: 13.06.2016.

25. ISTAT 2014, Aspetti della vita quotidiana, 2014; accessed: 16.05.2016

26. Signorelli C., Odone A., Bianco D., Di Vivo N., Bevere F., Health expenditure for prevention in Italy (2006-2013): descriptive analysis, regional trends and international comparisons, "Epidemiologia e Prevenzione" 2016; 40 (5): 374-380.

27. Meridiano della Sanità, Rapporto Meridiano Sanità 2015, http://download.repubblica.it/pdf/2015/salute/meridiano. pdf; accessed: 16.05.2016.

28. Ministero dell'Economia e della Finanza, Documento Economico Finanziario 2015.

29. Legge 31 dicembre 2009, n. 196, come modificata dalla legge 7 aprile 2011, n. 39, Capo I, Titolo VI articoli 21-24.

30. Ministero dell'Economia e delle Finanze, Dipartimento della ragioneria generale dello stato, Ispettorato Generale del Bilancio, Missioni e programmi delle amministrazioni centrali dello stato, Edizione Gennaio 2016.

31. Legge di stabilità n 190 del 23 Dicembre 2014. Art.1 comma 122-123.

32. Ministero dell'Interno, 2016, http://pacinfanziaeanziani. interno.gov.it, accessed: 16.05.2016.

33. Regione Marche, POR MARCHE FESR 2014-2020 - ASSE 1-OS 3. AZIONE 3.1.

34. Ministero della Salute, 1992 Progetto-obiettivo "Tutela della salute degli anziani".

35. Ministero della Salute, Piano Sanitario Nazionale 2001-03, http://www.salute.gov.it/imgs/C_17_pubblicazioni_949_allegato.pdf; accessed: 10.10.2016.

36. Ministero della Salute, Organigramma del Ministero della Salute (DPCM 11 febbraio 2014, n. 59), http://www.salute. gov.it/portale/ministro/p4_5_5_1.jsp?lingua=italiano\&label $=$ org\&menu=organizzazione; accessed: 10.12 .2016 .

37. Centro nazionale per la prevenzione e il controllo delle malattie $(\mathrm{Ccm})$, http://www.ccm-network.it/pagina. jsp?id=node/7; accessed: 10.12.2016.

38. Piano Nazionale della Prevenzione (National Health Plan), http://www.salute.gov.it/portale/temi/p2_4. jsp?area=prevenzione; accessed: 10.03.2016. 
39. AgeNaS, Local Health Authorities and District in Italy 2014, http://www.agenas.it/images/agenas/oss/distretti/ ASL_DISTRETTI_29_05_14.pdf; accessed: 10.03.2016.

40. Bassi M., Calamo-Specchia F., Faggiano F., Nicelli A.L., Ricciardi W., Signorelli C., Siliquini R., Valsecchi M., Rapporto Prevenzione 2015, Fondazione Smith Kline.

41. Ministero della Salute, Piano Nazionale della prevenzione 2007. Programma nazionale Guadagnare Salute, http:// www.ccm-network.it/pagina.jsp?id=node/9; accessed: 10.12.2016.

42. Ministero della Salute, Ondate di Calore, http://www.salute. gov.it/portale/caldo/homeCaldo.jsp; accessed: 27.12.2016.

43. Cutini R., Anziani. Salute e ambiente urbano, Maggioli Editore, 2013.

44. Ministero del Lavoro e delle Politiche Sociali, Decreto Direttoriale 807 del 19 ottobre 2012, http://www. italialavoro.it/wps/wcm/connect/685e59004fc6109aa 364a78911e39597/Decreto+Staffetta+generazionale. pdf?MOD=AJPERES; accessed: 27.12.2016.

45. Governo Italiano, Dipartimento per le Politiche della Famiglia, http://www.politichefamiglia.it/terza-eta/azioni-e-progetti/2015/invecchiamento-attivo-e-solidarieta-tragenerazioni/; accessed: 27.12.2016.

46. Città di Castiglion Fiorentino, Argento vivo: bando per volontari, http://www.comune.castiglionfiorentino.ar.it/comunicato.asp?com id=1935; accessed: 27.12.2016.

47. Bettio F., Simonazzi A., Villa P., Change in care regimes and female migration: the 'care drain' in the Mediterranean, "Journal of European Social Policy" 2006; 16 (3) 271-285

48. Ministero dell'Interno, Programma Nazionale Servizi di cura alla prima infanzia e agli anziani non autosufficienti. Versione 2.0, Luglio 2015, http://www.interno.gov.it/it/ temi/territorio/coesione-sociale; accessed: 27.12.2016.

49. Da Roit B., Sabatinelli S., Il modello mediterraneo di welfare tra famiglia e mercato, "Stato e Mercato" 2005; 74 267-290.

50. Happy Ageing, http://www.happyageing.it; accessed: 27.12.2016

51. Marazzi M.C. et al., Impact of the Community-Based Active Monitoring Program on the Long Term Care Services Use and In-Patient Admissions of the Over-74 Population, “Advances in Aging Research" 2015; 4: 187-194, http:// dx.doi.org/10.4236/aar.2015.46020; accessed: 27.12.2016.
52. Gruppo di Ricerca Geriatrica, Manuale Di coordinamento degli alzheimer caffe' della lombardia orientale, Brescia 2015, http://www.grg-bs.it/usr_files/alzheimer-caffe/manuale.pdf; accessed: 27.12.2016.

53. Forum delle Associazioni Familiari, Donare Memoria, http:// www.forumfamiglie.org/iniziative.php?\&iniziativa=13; accessed: 27.12.2016.

54. Jessoula M., Alti T., Italy: An uncompleted departure from Bismarck. A long goodbye to Bismarck, 2010.

55. Costa G., Prove di welfare locale, la costruzione di livelli essenziali di assistenza nella provincia di Cremona, Franco Angeli Ed., Milano 2009.

56. Costa G., Diritti in costruzione, presupposti per una definizione efficace dei livelli essenziali di assistenza sociale, Bruno Mondadori Ed., Milan 2012.

57. Regione Marche, Sintesi Censimento Progetti Ccm - Formez. Attività Fisica, http://www.azioniperunavitainsalute. it/files/materiali/in\%20evidenza/rapportoTecnico/Capitolo5AllegatoC5a5.pdf; accessed: 27.12.2016.

58. SPRINTT, Sarcopenia and Physical Railty IN older people: multi- component Treatment strategies, http://www. mysprintt.eu/it; accessed: 27.12.2016.

59. European Innovation Partnership on Active and Healthy Ageing, Reference Sites: excellent innovation for ageing. A European Guide, 2013.

60. Il progetto OPLON, 2016, http://www.oplon.eu/it_IT/; accessed: 27.12.2016.

61. Comune di Cerveteri, Orti Urbani, http://comune cerveteri.rm.it/comune/uffici-e-servizi/struttura-organizzativa-del-comune-di-cerveteri-delibera-199-2014/ concorsi-e-avvisi/avviso-pubblico-progetto-201 cgli-orti-urbani-coltivare-e-ridistribuire/progetto-orti-urbani/view; accessed: 27.12.2016.

62. Fara G.M., D'Alessandro D., L'invecchiamento della popolazione: riflessi sulla soddisfazione delle esigenze socio-assistenziali, "Techne" 2015; 9: 21-26.

63. Deriu F., URBACT II. Cities'Action for Healthy and Active Ageing. Baseline Study. March 2014, http://urbact.eu/sites/ default/files/healthy_ageing_baseline_study.pdf, accessed: 10.06.2016.

64. WHO, Global Age Friendly Cities. A guide. 2008, http:// www.who.int/ageing/publications/Global_age_friendly_cities_Guide_English.pdf; accessed: 10.06.2016. 